\title{
IRANO Okada 2015 Oncology Response Criteria
}

National Cancer Institute

\section{Source}

National Cancer Institute. IRANO Okada 2015 Oncology Response Criteria. NCI

Thesaurus. Code C158263.

Immunotherapy response assessment in neuro-oncology: a report of the RANO working group. (Okada H, Weller M, Huang R, Finocchiaro G, Gilbert MR, Wick W, Ellingson BM, Hashimoto N, Pollack IF, Brandes AA, Franceschi E, Herold-Mende C, Nayak L, Panigrahy A, Pope WB, Prins R, Sampson JH, Wen PY, Reardon DA. Immunotherapy response assessment in neuro-oncology: a report of the RANO working group. Lancet Oncol. 2015 Nov;16(15):e534-e542.) 